\title{
Epigallocatechin-3-gallate increases the formation of mineralized bone nodules by human osteoblast-like cells
}

\author{
Bahareh Vali ${ }^{\mathrm{a}}$, Leticia G. Rao ${ }^{\mathrm{b}}$, Ahmed El-Sohemy ${ }^{\mathrm{a}, *}$ \\ ${ }^{a}$ Department of Nutritional Sciences, Faculty of Medicine, University of Toronto, Toronto, Ontario, Canada M5S $3 E 2$ \\ ${ }^{\mathrm{b}}$ Calcium Research Laboratory, Division of Endocrinology and Metabolism, St. Michael's Hospital and Department of Medicine, University of Toronto, \\ Toronto, Ontario, Canada M5B 1 A6 \\ Received 11 March 2006; received in revised form 26 June 2006; accepted 27 June 2006
}

\begin{abstract}
Consumption of green tea, a rich source of epigallocatechin-3-gallate (EGCG), is associated with increased bone mineral density. However, the direct effects of this flavonoid on bone mineralization are not known. The present study demonstrates the effects of EGCG on the formation of mineralized bone nodules by SaOS-2 human osteoblast (HOB)-like cells. EGCG at concentrations of $1-5 \mu \mathrm{M}$ caused a dosedependent increase in the number and area of mineralized bone nodules as assessed by both von Kossa and alizarin red staining. EGCG also increased alkaline phosphatase activity, an early marker of osteoblastic differentiation. After $48 \mathrm{~h}$ of treatment, EGCG decreased protein levels of Runx2, a transcription factor that regulates osteoblast maturation by inhibiting late-stage differentiation. The observed effects of EGCG on bone formation by HOB-like cells suggest that EGCG may have beneficial effects on bone health.
\end{abstract}

(C) 2007 Elsevier Inc. All rights reserved.

Keywords: Epigallocatechin-3-gallate; Osteoporosis; SaOS-2 cells; Alkaline phosphatase; Runx2

\section{Introduction}

Osteoporosis is a complex disease influenced by genetic and environmental factors such as diet and lifestyle. Epidemiological studies have shown an association between a reduced risk of osteoporosis and the consumption of tea, including green tea [1-6]. Green tea is produced by drying fresh young leaves of the plant Camellia sinensis [7]. Unlike the preparation of black tea in which the leaves are fermented and oxidized, green tea is produced by steaming the leaves, which preserves their polyphenolic content [8]. The polyphenols comprise $\sim 30-40 \%$ of the solid extract of leaves and are mostly categorized as catechins (also called flavanols). The main green tea catechins are epigallocatechin-3-gallate (EGCG), epicatechin-3-gallate, epigallocatechin and epicatechin [9]. EGCG is the most abundant catechin in green tea that contributes to many of the beneficial health effects associated with consuming this beverage [10].

* Corresponding author. Tel.: +1 416946 5776; fax: +1 4169785882.

E-mail address: a.el.sohemy@utoronto.ca (A. El-Sohemy).
Bone integrity requires a tight coupling between the activity of bone-forming osteoblasts and bone-resorbing osteoclasts [11]. The phenotype of mature osteoblasts is characterized by their ability to synthesize and secrete molecules of the extracellular matrix. Osteoblasts regulate the mineralization of the formed matrix by producing alkaline phosphatase (ALP) [12]. This enzyme hydrolyzes phosphate esters to increase the local phosphate concentration and enhance mineralization of the extracellular matrix [13]. One of the characteristics of a mature osteoblast phenotype is the ability of the cells to synthesize ALP, which is considered an early marker of osteoblast differentiation. Differentiation of osteoblasts from multipotent mesenchymal stem cells is regulated by a member of the runt-domain gene family, known as Runt-related transcription factor-2 (Runx2) [1416]. Runx 2 has been shown to enhance osteoblast differentiation at an early stage but inhibit osteoblast maturation at late stages [17]. Runx2 is expressed as two isoforms, type I and type II, which differ only in their N-terminal sequences [18], and both isoforms are expressed in a number of osteoblast-like cell lines including SaOS-2 cells [19]. Although osteosarcoma cell lines such as SaOS-2 are transformed, they have a stable osteoblast-like phenotype in 
culture, making them a good model for studying the characteristics and functions of osteoblasts [20,21].

EGCG has been shown to induce apoptotic cell death in cultured mouse osteoclasts [22] and inhibit the formation of osteoclasts in a coculture system of mouse bone marrow cells and calvarial primary osteoblasts [23]. However, the effects of EGCG on osteoblastic bone formation are not known. In the present study, we investigated the direct effects of EGCG on osteoblastic bone formation using a human osteoblast (HOB)-like cell line. Our results demonstrate that EGCG causes a dosedependent increase in the formation of mineralized bone nodules, which was associated with a marked increase in osteoblast differentiation and a reduction in Runx2 protein levels.

\section{Materials and methods}

\subsection{Materials}

SaOS-2 cells were obtained from the American Type Culture Collection (Rockville, MD); Ham's F-12 medium was purchased from the Central Technical Services at the University of Toronto, and fetal bovine serum (FBS) was purchased from Cansera (Rexdale, Ontario). Reagents for Western blotting were obtained from BIORAD (Mississauga, Ontario). IgG-HRP-conjugated secondary antibody, Cruz Marker molecular weight standards and luminol reagent were purchased from Santa Cruz Biotechnology, Inc. (Santa Cruz, CA). Runx2 antibody was generously supplied by Dr. N. Elango (University of Texas Health Science Center, San Antonio, TX) [19]. ALP liquid reagent was purchased from TECO Diagnostics (Anaheim, CA). EGCG from green tea ( $>95 \%$ pure) and all other chemicals were purchased from Sigma (Oakville, Ontario).

\subsection{Cell culture}

SaOS-2 cells were grown in Ham's F-12 medium containing 10\% FBS, $28 \mathrm{mmol} / \mathrm{L}$ HEPES buffer $(\mathrm{pH}$ 7.35), $1.4 \mathrm{mmol} / \mathrm{L} \mathrm{CaCl}, 2 \mathrm{mmol} / \mathrm{L}$ glutamine and $1 \%$ antibiotic-antimycotic solution. Cells were seeded at a density of $5 \times 10^{3}$ cells per well in 24 -well plates and $1 \times 10^{5}$ cells per $75-\mathrm{cm}^{2}$ flask. The media were supplemented with $10 \mathrm{nM}$ dexamethasone (Dex) and $50 \mu \mathrm{g} / \mathrm{ml}$ ascorbic acid at the time of seeding (Day 0). On Day 8, $10 \mathrm{mM}$ $\beta$-glycerophosphate was added to the culture medium and the cells were treated with either vehicle $(0.1 \%$ PBS $)$ or varying concentrations of EGCG. This medium was replaced every $48 \mathrm{~h}$ until the end of the culture period [24].

\subsection{Determination and quantification of mineralized bone nodules}

On Day 17, cells seeded in 24-well plates were fixed in $4 \%$ paraformaldehyde overnight and the mineralized bone nodules were visualized by von Kossa [25] and alizarin red
[26] staining techniques. In order to detect calcium deposits, we stained cells with alizarin red $(40 \mathrm{mM}, \mathrm{pH}$ 4.2) for $10 \mathrm{~min}$ and then rinsed them with PBS. After the stain was extracted by $10 \%$ cetylpyridinium chloride in $10 \mathrm{mM}$ sodium phosphate $(\mathrm{pH} 7)$, the same nodules were stained with $5 \%$ silver nitrate. The nodules were then exposed to UV light for $30 \mathrm{~min}$ to detect phosphate deposits using the von Kossa method. Background color was removed by $5 \%$ sodium thiosulfate, and the cells were kept in $50 \%$ glycerol. Nodules were visualized using an inverted microscope, and the number and area of mineralized nodules were quantified by a FluorChem imaging system.

\subsection{ALP activity}

At different time points after treatment, cells seeded in 24-well plates were washed twice with $50 \mathrm{mM}$ Tris- $\mathrm{HCl}$ ( $\mathrm{pH} 7.3$ ) and kept in $0.05 \%$ Triton X-100 lysis buffer overnight at $-20^{\circ} \mathrm{C}$. The cells were later thawed on ice and harvested by scraping [24]. The ALP activity of the samples was determined by a colorimetric assay using an ALP reagent of $p$-nitrophenyl phosphate. The absorbance of $p$-nitrophenol formed by the hydrolysis of $p$-nitrophenyl phosphate, catalyzed by ALP, was measured at $410 \mathrm{~nm}$ by a Fusion plate reader 15 times every $2 \mathrm{~min}$. The protein content of the cell lysates was determined using the commercial Biorad protein assay [27]. The ALP activity of each sample was then normalized to its protein concentration and expressed as units per milligram of protein, with each unit of activity being defined as the amount of enzyme that produces $1 \mathrm{mmol} p$-nitrophenol/min.

\subsection{Western blot analysis}

Cells seeded in $75-\mathrm{cm}^{2}$ flasks were harvested at 6, 24 and $48 \mathrm{~h}$ after treatment by trypsin and disrupted in RIPA lysis buffer $(1 \times$ PBS, $1 \%$ Nonidet P-40, 0.5\% sodium deoxycholate, $0.1 \%$ SDS, $100 \mu \mathrm{g} / \mathrm{ml}$ PMSF, $45 \mu \mathrm{g} / \mathrm{ml}$ aprotinin, $1 \mathrm{mM}$ sodium orthovanadate and $50 \mu \mathrm{M}$ leupeptin) using a minihomogenizer. Cell lysates were

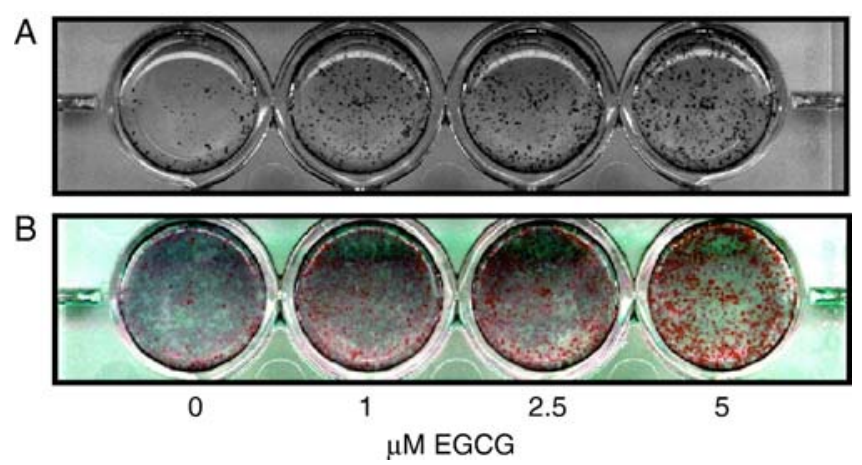

Fig. 1. Dose-dependent effects of EGCG on the formation of mineralized nodules in a 24-well plate fixed on Day 17 and stained by von Kossa (A) or alizarin red (B). Cells were treated with either vehicle or EGCG at concentrations of $1,2.5$ and $5 \mu \mathrm{M}$ on Day 10 . 

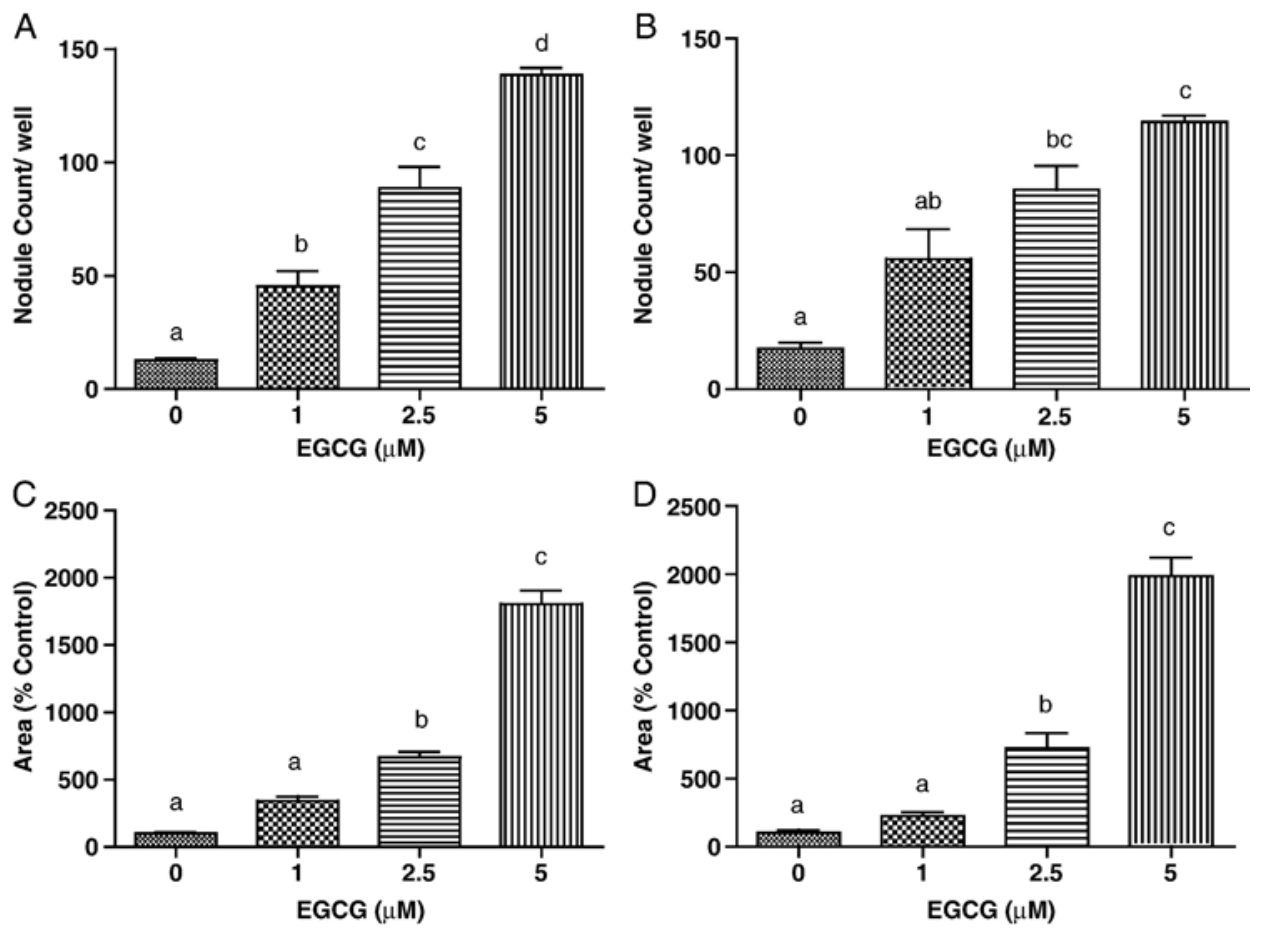

Fig. 2. Dose-dependent effects of EGCG on the number of mineralized bone nodules stained by von Kossa (A), the number of mineralized bone nodules as stained by alizarin red (B), the area of mineralized bone nodules stained by von Kossa (C) and the area of mineralized bone nodules stained by alizarin red (D). Values are expressed as mean \pm S.E.M. $(n=6)$. Bars with different letters are significantly different from each other at $P<.05$.

centrifuged for $10 \mathrm{~min}$ at $10,000 \mathrm{rpm}$, and the supernatants were stored at $-20^{\circ} \mathrm{C}$. Approximately $50 \mu \mathrm{g}$ of total protein from each sample was solubilized in $2 \times$ Laemmli buffer with 2-mercaptoethanol, heated at $95^{\circ} \mathrm{C}$ for $5 \mathrm{~min}$, electrophoresed using a $10 \%$ SDS-polyacrylamide gel and transferred to PVDF membranes using a semidry transfer apparatus. The membranes were blocked overnight with $5 \%$ nonfat milk in Tris-buffered saline $/ 0.05 \%$ Tween 20 (TBST) at $4^{\circ} \mathrm{C}$. The membranes were then incubated in anti-Runx2 antibody at a 1:1000 dilution for $2 \mathrm{~h}$ at room temperature. The antibody detects a $65-\mathrm{kDa}$ band that represents both type I and type II Runx2. Membranes were washed with TBST and probed with horseradish-peroxidase-conjugated antirabbit IgE antibody for $1 \mathrm{~h}$ at room temperature. After a final wash in TBST, the signals were detected by enhanced chemiluminescence. Exposure times were optimized for each treatment time $(6,24$ and $48 \mathrm{~h})$, and band intensities were compared relative to the intensity of the corresponding control band. To ensure equal protein loading, we stained membranes with $0.1 \%$ Coomassie brilliant blue solution containing 50\% methanol and $10 \%$ acetic acid. The membranes were destained using a solution containing $25 \%$ methanol and $7.5 \%$ acetic acid.

\subsection{Statistical analyses}

Results are expressed as mean \pm S.E.M. with six replicates in each group. Differences were analyzed using oneway and two-way analyses of variance followed by Bonferroni's post hoc test for multiple comparisons with a significance level of $P<.05$. All data were analyzed using GraphPad Prism Software, Version 4.00.

\section{Results}

\subsection{Effects of EGCG on the formation of mineralized bone nodules}

The first mineralized bone nodules formed by SaOS-2 cells were observed after 2 days of treatment (Day 10).

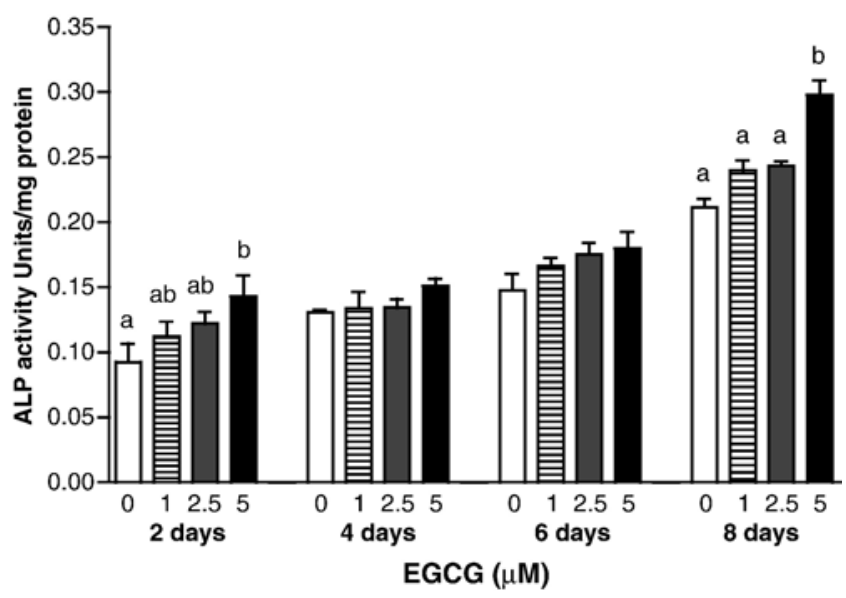

Fig. 3. The effects of EGCG on ALP activity were assessed in cells treated with vehicle or EGCG $(1-5 \mu \mathrm{M})$ for 2, 4, 6 and 8 days. Values are expressed as mean \pm S.E.M. $(n=6)$. Bars with different letters are significantly different from each other at $P<.05$. 
The nodules appeared three-dimensional in appearance under a phase contrast microscope and continued to grow until the end of the culture period. After staining the nodules on Day 17, the discrete mineralized bone nodules could be visualized by the naked eye as dark black spots after von Kossa staining (Fig. 1A) and as red-purple spots after staining with alizarin red (Fig. 1B). The addition of EGCG at concentrations as low as $1 \mu \mathrm{M}$ to the culture media increased the formation of mineralized nodules compared with control. EGCG caused a dose-dependent increase in the number and area of mineralized bone nodules as quantified using a FluorChem imaging system. Analysis of the results from von Kossa staining showed that at $5 \mu \mathrm{M}, \mathrm{EGCG}$ increased the number of nodules by $\sim 10$-fold compared with untreated cells $(12.6 \pm 1.5$ vs. $138.7 \pm 5.5, P<.01$; Fig. 2 A) and the area of nodules by $\sim 18$-fold (100.0 \pm 17.0 vs. $1802.0 \pm 175.6, P<.01$; Fig. 2 C). Analysis of the results from alizarin red staining demonstrated that $5 \mu \mathrm{M}$ EGCG resulted in an $\sim 7$-fold increase in the number of nodules $(17.3 \pm 4.5$ vs. $117.0 \pm 2.6, P<.01$; Fig. 2B) and in an increase in the area of nodules by $\sim 20$ fold (100.0 \pm 37.5 vs. $1985.0 \pm 235.2, P<.01$; Fig. 2D). A similar increase in both the number and area of nodules was also seen in cultures treated with $10 \mu \mathrm{M}$ EGCG (data

A

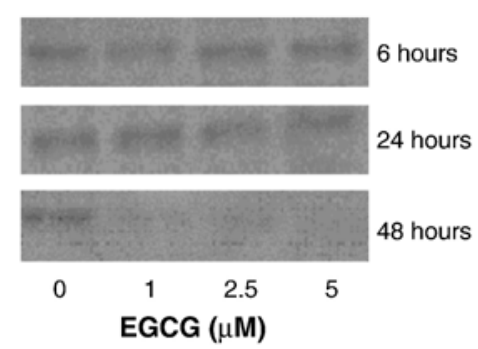

B

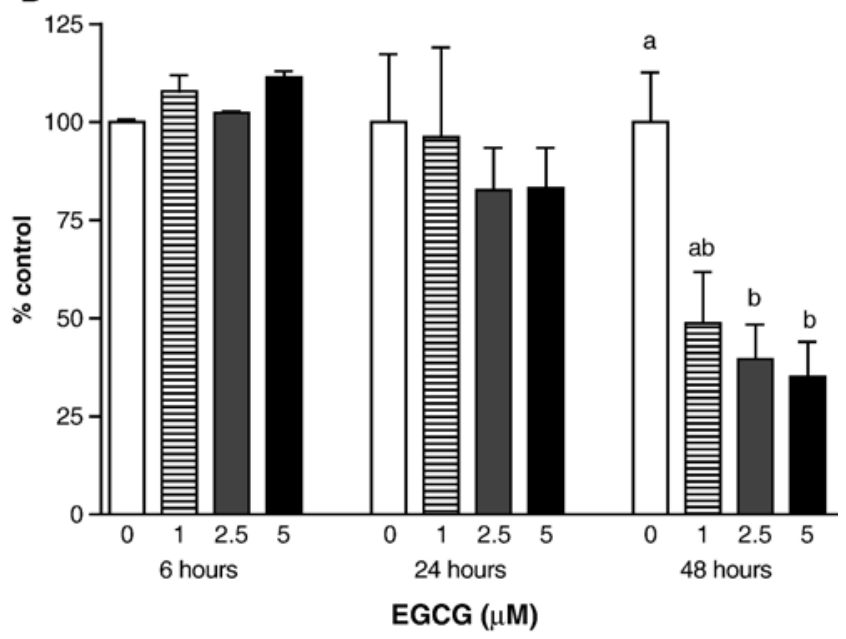

Fig. 4. (A) Representative Western blots of the effects of EGCG on Runx2 (types I and II) protein levels in SaOS-2 cells after 6, 24 and $48 \mathrm{~h}$ of treatment. (B) Band intensities were measured by densitometry, and values (means \pm S.E.M.) were expressed as a percentage of control at each time point $(n=6)$. Bars with different letters are significantly different from each other at $P<.05$. not shown). At this concentration, however, cells surrounding the nodules displayed marked changes in morphology and began to detach from the surface of the plate.

\subsection{Effects of EGCG on ALP activity}

Addition of EGCG to SaOS-2 cells cultured in 24-well plates showed a significant increase in the activity of ALP (Fig. 3). EGCG at a concentration of $5 \mu \mathrm{M}$ significantly increased ALP activity after 2 days of treatment. After 8 days of treatment, $5 \mu \mathrm{M}$ EGCG caused an $\sim 35 \%$ increase in ALP activity $(0.16 \pm 0.01$ vs. $0.22 \pm 0.01 \mathrm{U} / \mathrm{mg}$ protein, $P<.05$ ).

\subsection{Effects of EGCG on Runx2 protein level}

To determine whether the observed increase in the formation of mineralized nodules by EGCG-treated cells was associated with changes in the expression of Runx2 protein, we performed Western blot analyses on extracts of cells grown in the presence of increasing concentrations of EGCG after 6, 24 and $48 \mathrm{~h}$. Quantification of blots by density scanning of band intensities showed no significant effects of EGCG on Runx2 protein levels after 6 or $24 \mathrm{~h}$ of treatment (Fig. 4A and B). However, a significant decrease in Runx2 protein was observed after $48 \mathrm{~h}$ of treatment with 1-5 $\mu \mathrm{M}$ EGCG. At $5 \mu \mathrm{M}$ EGCG, Runx2 protein levels were reduced by $\sim 65 \%$ compared with controls $(100.0 \pm 21.9$ vs. $35.1 \pm 15.4, P<.01$; Fig. $4 \mathrm{~A}$ and B). A Coomassie blue staining of the membrane confirmed equal loading of protein (data not shown).

\section{Discussion}

In the present study, we have shown that EGCG, the most abundant flavonoid found in green tea, increases the formation of mineralized bone nodules from HOB-like cells by increasing osteoblastic differentiation. Our data provide some cellular and molecular evidence in support of the epidemiological associations between green tea consumption and a reduced risk of osteoporosis. Tea consumption has been associated with higher bone mineral density (BMD) $[1,2,5]$ and a lower risk of hip fractures in men and women $[3,4]$, although the effect of different types of tea consumed was not ascertained. In a study by Wu and Yang [6], in which $90 \%$ of tea drinkers regularly consumed green tea, a positive association was observed between tea and BMD of the total body, lumbar spine and hip regions in both men and women. Animal studies have also provided some evidence of the protective effect of green tea catechins against bone loss $[28,29]$. Investigation of the effects of green tea catechins on bone metabolic disorders using a model of chronic cadmiumpoisoned rats with increased bone resorption showed that a $0.5 \%$ catechin diet aided in normalizing decreased BMD and bone mineral content caused by cadmium intoxication [28]. Results from examining the role of whole aqueous $C$. sinensis extract on bone loss induced by estrogen deficiency in ovariectomized rats also suggest that tea catechins may be 
effective in preventing bone loss due to ovarian hormone deficiency [29].

EGCG has been shown to inhibit bone resorption by inducing apoptotic death of mouse osteoclast-like cells [22]. It was also demonstrated that EGCG inhibits the formation of osteoclasts in a coculture system of mouse bone marrow cells and primary osteoblastic cells [23]. Although these two studies support the inhibitory effect of EGCG on osteoclastic bone resorption, no studies have examined the effects of EGCG on osteoblastic differentiation or bone formation. To our knowledge, the present study is the first to investigate the direct effects of EGCG on bone-forming osteoblasts. We demonstrated that EGCG has a strong stimulatory effect on the formation of mineralized bone nodules in long-term cultures of human SaOS-2 cells. Osteosarcoma cell lines such as SaOS-2 have been developed to overcome the limitations of working with normal HOBs obtained either by human bone explant technique [30] or from human bone marrow [31]. HOB cells need a long time to grow in culture to become confluent, and only the first few passages can be used for experiments [32,33]. HOB cells grow slowly, which results in prolonged and costly maintenance, and their phenotypic properties tend to change after several passages. Because of the heterogeneous nature of these cells, their responses are also age dependent [30,34]. Although SaOS-2 is a transformed cell line, these cells have a stable osteoblast-like phenotype [20]. They not only grow rapidly but also form bone nodule-like structures and have been shown to differentiate into various stages in culture $[35,36]$. SaOS-2 cells develop different stages of differentiation in the presence and absence of Dex. Absence of physiological concentrations of Dex results in the development of a less-differentiated (Dex -cells) and continuous presence of Dex to a more-differentiated (Dex +cells) osteoblastic phenotype. The more-differentiated cultures express higher levels of ALP [20,35,37]. It is not exactly known which stage of osteoblastic differentiation SaOS-2 cells represent. However, based on different levels of ALP expression, they can qualitatively represent different stages of osteoblastic phenotype [21].

We used both von Kossa and alizarin red staining techniques to confirm the presence of hydroxyapatite $\left[\mathrm{Ca}_{10}\left(\mathrm{PO}_{4}\right)_{6}(\mathrm{OH})_{2}\right]$, which is the mineral part of the bone that consists predominantly of calcium and phosphate. Silver nitrate used in von Kossa staining is known to react specifically with phosphate deposits [38]. As the presence of phosphate alone does not necessarily confirm the existence of hydroxyapatite, we used an additional staining method (alizarin red) that detects calcium deposits. Since each of these staining techniques detects a different deposit and since each may have different nonspecific binding, it is possible that the two methods produce slightly different outcomes. Our results, however, show very similar increases in nodule formation by both techniques. Although it is not possible to determine at which stage of differentiation SaOS-2 cells are on the day of initiating treatment, we observed that the cells at this stage were starting to form the extracellular matrix, and the addition of $\beta$-glycerophosphate on Day 8 contributed to their maturation. Addition of EGCG at this point clearly accelerated the rate of cell maturation as shown by the increase in ALP (Fig. 3) and by the increase in bone nodule area and number (Fig. 2).

The process of formation of mineralized nodules has three main developmental stages: proliferation, development of the extracellular matrix and mineralization [12]. ALP activity is considered an early marker of osteoblastic differentiation because it generally increases during the differentiation stage and decreases when mineralization has progressed [39]. We observed a significant increase in ALP activity in cells treated with $5 \mu \mathrm{M}$ EGCG after 2 and 8 days of treatment. Although this effect was not significant on Days 4 and 6, probably due to the variability in ALP activity between samples within each group, a trend toward increased ALP activity in EGCG-treated cells was observed. The sampling time for ALP analysis was chosen based on our observation that the first mineralized nodules formed after 2 days of treatment with EGCG. These nodules continued to grow until the end of the culture period, which was 8 days after EGCG treatment. Although some studies using other osteoblastic cell lines have grown cells in differentiation media for up to 25 days [40], the SaOS-2 cells used in the present experiment begin to detach after a prolonged period in culture, which limited investigating the time to peak ALP activity. The stimulating effect of EGCG on ALP activity indicates an increase in the differentiation of SaOS-2 cells toward the mature bone-forming phenotype.

To determine a possible pathway through which EGCG may have increased the formation of bone nodules, we examined the levels of Runx2 protein in cells treated with EGCG at different time points using an antibody that detects both isoforms of Runx2. Differentiation of osteoblasts from multipotent mesenchymal cells is a process mainly controlled and regulated by the Runx 2 transcription factor, a member of the DNA binding runt-domain family [14,41]. Runx2-deficient calvarial cells in vitro have been shown to differentiate into both adipocytes and chondrocytes but totally lacked the ability to differentiate into osteoblasts [42]. However, after cells commit to the osteoblast lineage, the function of Runx2 may become different. Transgenic mice that overexpress Runx 2 in their osteoblasts had severe osteopenia and bone fractures, with an increase in osteoblast number from an early developmental stage, but impaired osteoblast function in matrix production and mineralization. Osteoblast maturation in these mice was shown to be inhibited at a late stage, and the failure in terminal differentiation resulted in bone fragility, demonstrating that Runx2 inhibits osteoblast differentiation at a late stage [17]. Our results showed a decrease in Runx2 after $48 \mathrm{~h}$ of treatment with EGCG. The reduction in the level of Runx2 protein by EGCG was observed with $1 \mu \mathrm{M}$ and reached a maximal inhibitory effect with $5 \mu \mathrm{M}$. Since Runx2 is known to negatively regulate late-stage osteoblast 
differentiation and restrain osteoblast maturation, the inhibitory effect of EGCG on Runx 2 protein provides a potential mechanism by which this compound increases the formation of mineralized bone nodules. By blocking the synthesis of Runx 2 protein, EGCG may enhance the differentiation of osteoblasts to progress to the maturation level, thereby increasing the mineralization of bone matrix and forming more bone nodules.

In summary, our results demonstrate that EGCG increases the differentiation and formation of mineralized bone nodules from HOB-like cells and suggest that green tea catechins may have beneficial effects on bone health.

\section{References}

[1] Hegarty VM, Helen MM, Khaw K. Tea drinking and bone mineral density in older women. Am J Clin Nutr 2000;71:1003-7.

[2] Hoover PA, Webber CE, Beaumont LF, Blake JM. Postmenopausal bone mineral density: relationship to calcium intake, calcium absorption, residual estrogen, body composition and physical activity. Can J Physiol Pharmacol 1996;74:911-7.

[3] Kanis J, Johnell O, Gullberg B, Allande E, Elffors L, Ranstam J, et al. Risk factors for hip fracture in men from southern Europe: the MEDOS Study. Mediterranean Osteoporosis Study. Osteoporos Int 1999;9:45-54.

[4] Johnell O, Gullberg B, Kanis JA, Allander E, Elffors L, Dequeker J, et al. Risk factors for hip fracture in European women: the MEDOS Study. Mediterranean Osteoporosis Study. J Bone Miner Res 1995;10:1802-15.

[5] Chen Z, Pettinger MB, Ritenbaugh C, LaCronix AZ, Robbins J, Caan $\mathrm{BJ}$, et al. Habitual tea consumption and risk of osteoporosis: a prospective study in the women's health initiative observational cohort. Am J Epidemiol 2003;158:772-81.

[6] $\mathrm{Wu} \mathrm{CH}$, Yang YC. Epidemiological evidence of increased bone mineral density in habitual tea drinkers. Arch Intern Med 2002;162:1001-6.

[7] Yang CS, Landau JM. Effects of tea consumption on nutrition and health. J Nutr 2000;130:2409-12.

[8] Brown MD. Green tea (Camellia sinensis) extracts and its possible role in the prevention of cancer. Altern Med Rev 1999;4:360-70.

[9] Sato T, Miyata G. The nutraceutical benefit: part I. Green tea. Nutrition 2000;16:315-7.

[10] Higdon JV, Frei B. Tea catechins and polyphenols: health effects, metabolism and antioxidant function. Crit Rev Food Sci Nutr 2003;43:89-143.

[11] Riggs BL, Melton LJ. The prevention and treatment of osteoporosis. N Engl J Med 1992;327:620-7.

[12] Aubin JE. Advances in osteoblast lineage. Biochem Cell Biol 1998;76:899-910.

[13] Lian BJ, Stein GS, Canalis E, Robey PG, Boskey AL. Bone formation: osteoblast lineage cells, growth factors, matrix proteins and the mineralization process. In: Favus MJ, editor. Primer on the metabolic bone disease and disorder of mineral metabolism. Philadelphia: Lippincott Williams \& Williams; 1999.

[14] Ducy P, Zhang R, Geoffroy V. Osf2/Cbfa1: a transcriptional activator of osteoblast differentiation. Cell 1997;89:747-54.

[15] Komori T, Yagi H, Nomura S. Targeted disruption of Cbfa1 results in a complete lack of bone formation owing to maturational arrest of osteoblasts. Cell 1997;89:755-64.

[16] Otto F, Thornell AP, Crompton T. Cbfa1, a candidate gene for cleidocranial dysplasia syndrome, is essential for osteoblast differentiation and bone development. Cell 1997;89:765-71.

[17] Liu W, Toyosawa S, Furuichi T, Kanatani N, Yoshida C, Liu Y, et al. Overexpression of $\mathrm{Cbfa} 1$ in osteoblasts inhibits osteoblast maturation and causes osteopenia with multiple fractures. J Cell Biol 2001;155:157-66.

[18] Harada H, Tagashira S, Fujiwara M, Ogawa S, Katsumata T, Yamaguchi A, et al. Cbfa1 isoforms exert functional differences in osteoblast differentiation. J Biol Chem 1999;274:6972-8.

[19] Sudhakar S, Katz MS, Elango N. Analysis of type-I and type-II RUNX2 protein expression in osteoblasts. Biochem Biophys Res Commun 2001;286:74-9.

[20] Rodan SB, Imai Y, Thiede MA, Wesolowski G, Thomson D, BarShavit Z, et al. Characterization of a human osteosarcoma cell line SaOS-2 with osteoblastic properties. Cancer Res 1987;47:49-66.

[21] Rao LG, Murray TM. Studies of human osteoblasts in vitro: estrogen actions and interactions with other hormones at different stages of differentiation. Drug Dev Res 2000;49:174-86.

[22] Nakagawa H, Wachi M, Woo J, Kato M, Kasai S, Takahashi F, et al. Fenton reaction is primarily involved in a mechanism of (-)-epigallocatechin-3-gallate to induce osteoclastic cell death. Biochem Biophys Res Commun 2002;292:94-101.

[23] Yun JH, Pang EK, Kim CS, Yoo YJ, Cho KS, Chai JK, et al. Inhibitory effects of green tea polyphenol (-)-epigallocatechin gallate on the expression of matrix metalloproteinase- 9 and on the formation of osteoclasts. J Periodontal Res 2004;39(5):300-7.

[24] Rao LG, Liu LJ, Murray TM, McDermott E, Zhang X. Estrogen added intermittently but not continuously, stimulates differentiation and bone formation in SaOS-2 cells. Biol Pharm Bull 2003;26:936-45.

[25] Rao LG, Liu LJ, Murray TM, McDermott E. 17-B estradiol stimulates mineralized bone formation when added intermittently to SaOS-2 cells. Drug Metabol Drug Interact 2001;18:149-58.

[26] Hale LV, Ma YF, Santerre RF. Semi-quantitative fluorescence analysis of calcein binding as a measurement of in vitro mineralization. Calcif Tissue Int 2000;67:80-4.

[27] Bradford MM. A rapid and sensitive method for the quantification of microgram quantities of protein utilizing the principle of protein-dye binding. Anal Biochem 1976;72:248-54.

[28] Choi JH, Rhee IK, Park KY, Kim JK, Rhee SJ. Action of green tea catechin on bone metabolism disorder in chronic cadmium-poisoned rats. Life Sci 2003;73:1479-89.

[29] Das AS, Mukherjee M, Mitra C. Evidence for a prospective antiosteoporosis effect of black tea (Camellia sinensis) extract in a bilaterally ovariectomized rat model. Asia Pac J Clin Nutr 2004;13:210 -6.

[30] Kung-Sutherland MS, Rao LG, Muzzafar SA, Wylie JN, Wong MM, McBroom R, et al. Age-dependent expression of osteoblastic phenotypic markers in normal human osteoblasts cultured long term in the presence of dexamethasone. Osteoporos Int 1995;5:335-43.

[31] Kassem M, Risteli L, Mosekilde L, Melsen F, Eriksen EF. Formation of osteoblast-like cells from human mononuclear bone marrow cultures. APMIS 1991;99:269-74.

[32] Robey PM, Termine JD. Human bone cells in vitro. Calcif Tissue Int 1985;37:453-60

[33] Wong MM, Rao LG, Ly H, Hamilton L, Sturtridge W, McBroom R, et al. Long term effects of physiological concentrations of dexamethasone on human bone-derived cells. J Bone Miner Res 1990;5:803-13.

[34] Matsuyama T, Lau K, Wergedal JE. Monolayer cultures of normal human bone cells contain multiple subpopulations of alkaline phosphatase positive cells. Calcif Tissue Int 1990;47:276-83.

[35] Manduca P, Sanguineti C, Pistone M, Boccignone E, Sanguineti F, Santolini $\mathrm{F}$, et al. Differential expression of alkaline phosphatase in clones of human osteoblast-like cells. J Bone Miner Res 1993;8: 291-300.

[36] Rao LG, Wylie JN, Kung-Sutherland MS, Murray TM. 17 Beta estradiol enhances the stimulatory effect of 1,25 dihydroxy vitamin D3 on alkaline phosphatase activity in human osteosarcoma SaOs- 2 cells in a differentiation-dependent manner. J Endocrinol 1996;148:181-7.

[37] Rao LG, Wylie JN, Kung-Sutherland MS, Murray TM. 17 Betaestradiol and parathyroid hormone potentiate each others stimulatory effects on alkaline phosphatase activity in SaOS-2 cells in a differentiation-dependent manner. Endocrinology 1994;134:614-20. 
[38] Meloan SN, Puchtler H. Chemical mechanisms of staining methods: von Kossa's technique. What von Kossa really wrote and a modified reaction for selective demonstration of inorganic phosphate. J Histotechnol 1985;8:11-3.

[39] Aubin JE. Regulation of osteoblast formation and function. Rev Endocr Metab Disord 2001;2:81-94.

[40] Maeda T, Matsunuma A, Kawane T, Horiuchi N. Simvastatin promotes osteoblast differentiation and mineralization in MC3T3-E1 cells. Biochem Biophys Res Commun 2000;280:874-7.
[41] Banarjee C, McCabe LR, Choi JY, Hiebert SW, Stein JL, Stein GS, et al. Runt homology domain proteins in osteoblasts differentiation: AML3/Cbfa1 is a major component of bone-specific complex. J Cell Biochem 1997;66:1-8.

[42] Kobayashi H, Gao Y, Ueta C, Yamaguchi A, Komori T. Multilineage differentiation of Cbfa1-deficient calvarial cells in vitro. Biochem Biophys Res Commun 2000;273:630-6. 